\title{
Surface modification of tungsten and tungsten-tantalum alloys exposed to high-flux deuterium plasma and its impact on deuterium retention
}

\author{
Y. Zayachuk', b *, M. H. J. 't Hoen ${ }^{\mathrm{c}}$, P. A. Zeijlmans van Emmichoven ${ }^{\mathrm{c}}$, D. Terentyeva, I. \\ Uytdenhouwen $^{\mathrm{a}}$ and $\mathrm{G}$. van Oost ${ }^{\mathrm{b}}$
}

${ }^{a}$ SCK•CEN, Association EURATOM-Belgian State, partner in the Trilateral Euregio Cluster, Boeretang 200, BE-2400 Mol, Belgium

${ }^{\mathrm{b}}$ Department of Applied Physics, Ghent University, St. Pietersnieuwstraat 41, 9000 Ghent, Belgium

${ }^{c}$ FOM Institute DIFFER - Dutch Institute for Fundamental Energy Research, Association EURATOM-

FOM, partner in the Trilateral Euregio Cluster, Edisonbaan 14, 3439 MN Nieuwegein, the Netherlands

Samples of tungsten and tungsten-tantalum alloy (with 5 mass percent Ta) were exposed to high-flux deuterium plasma at different fluences. The surface modification was studied with scanning electron microscopy, and deuterium retention was measured by thermal desorption spectroscopy. In the high fluence range of $\sim 3.5^{*} 10^{26}-$ $10^{27} \mathrm{~m}^{-2}$ the surface of the $\mathrm{W}$ samples exhibited heavy blistering, while blisters on the surface of W-Ta were considerably smaller in size and number. Deuterium retention in this fluence range was found to be systematically higher in $\mathrm{W}$ than in $\mathrm{W}$-Ta. Correlation between the evolution of the blistering patterns and the TDS spectra as a function of fluence suggests that trapping in the sub-surface cavities associated with blisters is the predominant trapping mechanism in tungsten in case of high fluence exposures. We attribute the lower retention in $\mathrm{W}$-Ta under the investigated conditions to the weaker blistering.

Keywords: Blistering, deuterium retention, tungsten, tungsten-tantalum, Pilot-PSI

\section{Introduction}

Tungsten is suggested to be used as divertor material in ITER and in future fusion reactors [1]. The problem of the use of tungsten is its high ductile-to-brittle transition temperature (DBTT) [2] and therefore high brittleness at the temperature of operation. Also, being used as a plasma-facing material, tungsten might be prone to material degradation as a result of the transient heat loads due to ELMs [3].

In order to improve the ductility of tungsten, the alloying of tungsten with some ductile component was proposed. One such alloying component was tantalum [4].

It appears that the ductility of W-Ta alloy did not improve compared to pure tungsten [5]. However, in certain conditions W-Ta appears to have better resistance to the surface degradation (cracking and roughening) induced by the transient ELM-like heat loads [6].

One of the requirements to the potential plasma facing candidate material is low tritium retention, which is one of the advantages of tungsten [7]. Therefore, an important aspect which needs to be evaluated with respect to use of other tungsten-based materials is the comparison of hydrogen isotopes retention with that of pure material.

The studies of retention in W-Ta alloy started only recently [8-11]. In our previous work [10] we showed that there is no systematic difference in retention between $\mathrm{W}$ and $\mathrm{W}$-Ta exposed to highflux deuterium plasma, in the fluence range of $\sim 5^{*} 10^{25} \mathrm{~m}^{-2}$. However, we observed the history effect, indicating that the exposure to high-flux plasma, even though the ion energy is well below the displacement damage threshold, leads to the significant generation of trapping sites for deuterium, which we identified as vacancy-type defects generated as a result of plastic deformation due to high mechanical stresses created by the deuterium concentration strongly exceeding the solubility limit. On the other hand it is well known that deuterium implantation often leads to the formation of subsurface cavities and associated surface blistering [12]. The comparison of deuterium retention in $\mathrm{W}$ and $\mathrm{W}$-Ta under the conditions in which significant blistering occurs has never been performed.

In this work we present the first results on comparison of surface modification of W and W-Ta under high-flux deuterium plasma exposure and investigate the impact of this modification on deuterium retention.

\section{Experiment}

The experimental setup was the same as the one used for the experiments described in [9]. Here it is briefly summarized. Plasma exposures were performed using the linear plasma generator PilotPSI at the FOM Institute DIFFER [13]. The plasma source of Pilot-PSI is based on a cascaded arc discharge with pulsed magnetic field. Electron temperature and density profiles (and therefore also particle and heat flux profiles) within the plasma beam are roughly Gaussian with FWHM of $\sim 1 \mathrm{~cm}$. 
The ion flux arriving at the surface of the specimen is calculated from the electron temperature and density measured by Thomson scattering. The surface temperature of a specimen is monitored by an IR camera.

Powder metallurgy $\mathrm{W}$, and powder metallurgy W-Ta alloy containing 5 mass \% of Ta were investigated. The materials were provided by Plansee. All investigated polycrystalline samples were mechanically polished to mirror finish and then annealed in vacuum at $1300 \mathrm{~K}$ for 1 hour. During annealing the samples were not recrystallized. The samples were discs of $20 \mathrm{~mm}$ in diameter and thickness of $1 \mathrm{~mm}$.

The experimental procedure was the following. During deuterium exposures each investigated sample was exposed to certain fluence. Pilot-PSI cannot operate in steady state, and therefore it is not possible to have long exposure times (i.e., high fluences) in single continuous exposure. Therefore, in order to reach high accumulated fluences, it is necessary to perform several consecutive shots. For exposures of different samples we used identical reference shots, varying their number in order to vary the fluence. The parameters of the reference shot were the following - ion flux $\sim 8 * 10^{23}-10^{24} \mathrm{~m}^{-}$ ${ }^{2} \mathrm{~s}^{-1}$, surface temperature 460-510 K, ion energy 50 $\mathrm{eV}$, duration $70 \mathrm{sec}$, ion fluence $\sim 5^{*} 10^{25} \mathrm{~m}^{-2}$. The time lag between individual shots is determined by the time necessary for the magnetic coils of PilotPSI to cool down to the nominal level, and is close to $10 \mathrm{~min}$.

Plasma-induced surface modification was studied with a scanning electron microscope JEOL JSM-840, at an acceleration voltage $15 \mathrm{kV}$.

Retention was studied with TDS. The maximum temperature was $1273 \mathrm{~K}$, the temperature ramp was $0.5 \mathrm{~K} / \mathrm{s}$, and the holding time at the maximum temperature was 5 minutes. The release fluxes of molecular $\mathrm{HD}$ and $\mathrm{D}_{2}$ were measured by a quadrupole mass spectrometer. The time lag between the plasma exposure and the TDS measurement for each sample was one week, ensuring that weakly bound and solute deuterium atoms are released during the waiting time, so that only the trapped content is observed.

In order to study the influence of high flux, high fluence plasma exposure on surface modification in the subsequent exposures, after TDS measurement the samples were exposed again, this time to a single reference shot. Again surface imaging and TDS were performed. The TDS measurements were done about 4 month after the exposure.

\section{Experimental results}

\subsection{Surface modification of $W$ and $W$-Ta}

Fig. 1 presents the results of SEM imaging of the surfaces of the $\mathrm{W}$ samples exposed to different number of plasma shots. It is evident that the exposure causes strong blistering of the $\mathrm{W}$ surface. As the accumulated fluence increases, evolution of the surface modification pattern occurs.

The surface modification starts with the appearance of large number of small blisters (up to a few hundred nanometers in diameter). After exposure to higher fluences the density of small blisters considerably decreases in favor of the growth of larger blisters (up to a few micrometers in diameter).

Fig. 2 presents images of the surface of $\mathrm{W}$ 5\%Ta samples exposed to different fluences. Only weak blistering occurs and the surfaces of the samples exposed to 7 and 20 reference shots feature virtually identical blistering patterns (with small blisters with diameters up to a few hundred nanometer).

Fig. 3a presents the blistering pattern appearing on the surface of the $\mathrm{W}$ sample which was exposed to the highest plasma fluence of 20 shots, then underwent TDS and additional exposure to a single reference shot. This additional shot did not lead to the further evolution of the pattern, i.e. to further growth of large blisters. Instead, the large amount of small blisters appear on the surface, so that the overall pattern looks like a superposition of the patterns corresponding to exposures to 1 and to 20 reference shots.

Fig. 3b presents the image of the surface of the $\mathrm{W}-5 \%$ Ta sample exposed to highest fluence of 20 shots then underwent TDS and additional exposure to a single reference shot. No noticeable change of the blistering pattern is observed.

Comparison of Figs. 1 and 2 shows that there is a significant difference between blistering patterns of the surfaces of $\mathrm{W}$ and $\mathrm{W}$-Ta. While the surface of $\mathrm{W}$ becomes heavily blistered, the surface of $\mathrm{W}-\mathrm{Ta}$, even after prolonged exposure and large accumulated fluence, features only small densities of small blisters.

\subsection{Deuterium retention in $\mathrm{W}$ and $\mathrm{W}-\mathrm{Ta}$}

Fig. 4 presents measured release spectra of samples of $\mathrm{W}$ exposed to different accumulated fluences, indicating release of both $\mathrm{D}_{2}$ and HD. It is evident that the desorption spectra of samples of $\mathrm{W}$ are modified significantly when the accumulated fluence increases.

The $D_{2}$ release spectrum features the wellpronounced low-temperature (in the following referred to as LT) and high-temperature (HT) release components. Upon exposure to 1 reference shot the LT component with the maximum at $\sim 470$ $\mathrm{K}$ is dominant. With the increase of fluence the height and integrated area of the LT component monotonically decreases and its position shifts to $\sim 510 \mathrm{~K}$ (upon exposure to 7 and 20 reference shots). In the same time, the height and integrated 
area of the HT component (whose maximum is at $\sim 750 \mathrm{~K}$ independently on the fluence) increases.

The change between the spectra corresponding to 1 and 7 shots (increase of fluence from $\sim 5^{*} 10^{25}$ $\mathrm{m}^{-2}$ to $\sim 3.5^{*} 10^{26} \mathrm{~m}^{-2}$ ) is significant; on the other hand, the change between spectra corresponding to 7 and 20 shots (change of fluence from $\sim 3.5 * 10^{26}$ $\mathrm{m}^{-2}$ to $\sim 10^{27} \mathrm{~m}^{-2}$ ) is considerably smaller although the general trend of the evolution of the particular spectral components remains the same.

Fig. 5 presents the TDS spectra obtained after the additional exposure of $\mathrm{W}$ sample pre-exposed to the highest fluence of 20 shots. The spectrum still features the distinct LT and HT components. However, just like in the case of the $\mathrm{W}$ sample exposed to 1 shot, the LT component at $\sim 515 \mathrm{~K}$ is predominant. On the other hand, position of the HT component shifts to lower temperature of $\sim 690 \mathrm{~K}$. The total retention is noticeably smaller than it was after the first exposure. However, this is understandable, as the exposure fluence in the additional exposure was 20 times lower than in the first one, moreover, the time lag between exposure and TDS was much longer (4 month and 1 week, respectively).

Fig. 6 presents measured release spectra of samples of $\mathrm{W}-5 \% \mathrm{Ta}$. The spectrum of the sample exposed to 1 plasma shot was not collected, so only the spectra corresponding to 7 and 20 shots are presented.

These spectra also contain two components, at $\sim 490 \mathrm{~K}$ and at $\sim 670-680 \mathrm{~K}$. The peak at medium temperature appears not to be an independent release component but the result of the superposition of the LT and HT components. This is shown in the Fig. 7, where the decomposition peaks were constructed in the following way - the scaled low-temperature part of the LT peak was connected to the high-temperature part of the HT peak and vice versa. The overall shape of the $D_{2}$ release spectra is similar for both fluences, but again redistribution of intensities and integrated areas between peaks occurs as fluence increases. The change of the shape of the spectrum with the increase of fluence follows the same behavior as in the case of pure $\mathrm{W}$ - when fluence increases, the LT component decreases whereas the HT component increases.

It should be emphasized that at high exposure fluences the shapes of the spectra of $\mathrm{W}$ and $\mathrm{W}-\mathrm{Ta}$ are noticeably different (Fig. 7). The LT components of $\mathrm{D}_{2}$ spectra of both materials are of similar heights and approximately at the same temperature of $\sim 500 \mathrm{~K}$, Fig. 7 . At the same time the HT spectral components for W and W-Ta strongly differ. For W-Ta this component does not dominate the total retention, as is the case for $\mathrm{W}$ and is shifted to somewhat lower temperature of $\sim 670 \mathrm{~K}$.

Fig. 8 presents the dependence of the total retention on the number of plasma shots on the samples. Total retention was calculated by summation of deuterium amounts released both as molecular $\mathrm{D}_{2}$ and molecular HD. It should be noted that in the current measurements the fraction of deuterium released as molecular HD was low and did not exceed $15 \%$. The figure contains both the measurements of the present work, where plasma shots were directly following each other (hollow symbols), and from the previous work [14] where each shot was performed as an individual exposure with the TDS measurement following each exposure (filled symbols).

The general trend is towards the saturation of retention as a function of number of exposure shots. Fig. 8 also shows that there is no systematic difference between retention in $\mathrm{W}$ and $\mathrm{W}-\mathrm{Ta}$ at lower fluences. However, at high fluences, the retention in W-Ta is consistently below the corresponding value for $\mathrm{W}$.

\section{Discussion}

The presented comparative study of $\mathrm{W}$ and $\mathrm{W}$ 5\%Ta exposed to high fluences of high flux deuterium plasma reveals: (i) significantly stronger blistering in W; (ii) significantly higher D retention in W. Combining these two observations suggests a correlation between blistering and retention.

To justify this suggestion we consider the evolution of the observed blistering patterns along with the evolution of the corresponding TDS spectra. Especially in case of W, where blistering is strong and also strongly changes with exposure fluence, a noticeable correlation can be found. It is evident that whenever large densities of small blisters are observed (at lowest exposure fluences of 1 reference shot, both during first and second exposures) the total retention is dominated by the LT release component (compare Fig. 4 and 5). This suggests that LT component can be attrbuted to the deuterium release from the sub-surface cavities related to the small blisters. On the other hand, the LT component remains quite strong even for $\mathrm{W}$ samples exposed to 7 and 20 reference shots when small blisters have mostly disappeared. This suggests that sub-surface cavities corresponding to the small blisters are not the only source of this component. In earlier work [10], [15] the release peak at similar temperatures has been observed for samples exposed to similar high-flux plasma, which did not feature noticeable blistering. It was associated with trapping in monovacancies. Taking into account that the trapping energies for deuterium in vacancies and for that retained in molecular form inside the cavities are both close to $\sim 1.45 \mathrm{eV}$ [16], [17] it is reasonable to assume that the LT peak is due to detrapping from both the vacancies and cavities related to the small blisters.

It is also evident that when small blisters have disappeared and the blistering pattern is dominated by the large ones, the HT component prevails. This in turn suggests that HT component is due to the 
release from the sub-surface cavities corresponding to the large blisters. Since the HT release component dominates the retention at high exposure fluences, it can be concluded that at high fluence the majority of the retained deuterium is trapped in sub-surface cavities related to large blisters.

The question arises - why does release from cavities related to blisters of different sizes occurs at essentially different temperatures? It should be noted that the cavities underneath the small blisters are at considerably smaller depths from the surface than the cavities underneath the large ones [18]. Even when the trapping energies in the different cavities are similar, this different depth will lead to the observed differences in release temperature

The abovementioned considerations suggest the reason for the difference in retention between $\mathrm{W}$ and W-Ta. SEM imaging makes it evident that blistering of W-Ta is considerably weaker than in W. Therefore, assuming that at higher fluences retention is mainly due to the trapping in subsurface cavities associated with blisters, the considerably weaker blistering in $\mathrm{W}$-Ta leads to lower retention.

Additional evidence that under investigated conditions retention at high fluences is dominated by blistering, or more generally by the plasmainduced defects, rather than being dominated by diffusion and trapping on pre-existing defects, is the fact that retention saturates with fluence. In case of the diffusion-controlled process involving trapping on pre-existing defects it would rather increase $F^{0.5}$ $-F^{0.7}$, where $F$ is fluence [19]. This also suggests that plasma-induced material modification does not increase indefinitely, but saturates at certain level. Importantly, this is lower for $\mathrm{W}-5 \%$ Ta than for $\mathrm{W}$.

Several possible reasons for the much weaker blistering of W-Ta compared to $\mathrm{W}$ can be suggested. One is the difference in the elastic properties of the alloy as compared to the pure material. It is reasonable to assume that the elastic stiffness coefficients of the alloy will strongly differ from those of pure $\mathrm{W}$ since the coefficients of $\mathrm{W}$ and Ta are known to be significantly different (C11 - $522 \mathrm{GPa}$ for W/262 GPa for Ta; C12 - $204 \mathrm{GPa} /$ $156 \mathrm{GPa}$; C44 - $161 \mathrm{GPa} / 83 \mathrm{GPa}$ [20]; see also [21]). Another possible reason is the difference in stability of plasma-induced non-equilibrium vacancies due to the presence of $\mathrm{Ta}$ atoms. It is known [22] that an efficient mechanism for the stabilization of vacancies (thus preventing them from coalescence and hindering the nucleation and growth of sub-surface cavities) is the formation of vacancy-impurity pairs, and Ta might play a role of such an impurity.

To conclude the discussion we compare our results with the recently published studies of retention in $\mathrm{W}$-Ta alloys exposed to deuterium ions at low flux [11]. Using $1 \mathrm{keV}$ ion beams with ion flux of $\sim 10^{19} \mathrm{~m}^{-2} \mathrm{~s}^{-1}$, exposing the samples at surface temperature of $\sim 330 \mathrm{~K}$ to fluences in the range of $\sim 2.3 * 10^{23}-1.2 * 10^{24} \mathrm{~m}^{-2}$, the authors found that deuterium retention in $\mathrm{W}-1 \% \mathrm{Ta}$ and $\mathrm{W}-5 \% \mathrm{Ta}$ is significantly higher than in $\mathrm{W}$, in contrast to our data. As possible explanation for this discrepancy we suggest the difference in flux. The authors of Ref. [11] used much lower ion fluxes; therefore the concentration of the solute deuterium during the implantation was lower as well. Thus it is reasonable to assume that the material modification was minor compared to our exposure conditions. Thus, retention at low flux was most probably dominated by trapping on pre-existing defects. The authors of Ref. [11] attribute higher deuterium retention $\mathrm{W}$-Ta as compared to $\mathrm{W}$ to the higher concentration of the pre-existing trapping sites.

For our high ion flux conditions we have shown that deuterium retention is strongly influenced by the plasma-induced material modification. This modification predominantly determines the difference in retention between $\mathrm{W}$ and W-Ta and not the initial difference in microstructure.

Thus, we point out the more general significance of our findings. Namely, it indicates that in assessing the retention properties of different materials, not only absolute retention at certain conditions, but also the plasma-induced modifications need to be compared.

\section{Conclusions}

We have compared the deuterium retention and surface modification of $\mathrm{W}$ and $\mathrm{W}-5 \% \mathrm{Ta}$ exposed to high-flux $\left(8 * 10^{23}-10^{24} \mathrm{~m}^{-2} \mathrm{~s}^{-1}\right)$ plasmas at surface temperatures in the range of $460-510 \mathrm{~K}$, using TDS and SEM.

In the high fluence range of $3.5 * 10^{26}-10^{27} \mathrm{~m}^{-2}$ SEM imaging has demonstrated that $\mathrm{W}$ exhibits considerably stronger blistering than W-Ta. The blistering pattern evolves with fluence. For W, the density of blisters decreases whereas their size increases. For W-5\%Ta the blister patterns at higher fluences clearly consist in much smaller densities of only small blisters, which do not significantly change with fluence.

With TDS it was found that at high exposure fluences $\left(3.5^{*} 10^{26}-10^{27} \mathrm{~m}^{-2}\right)$ the total retention in W is systematically higher and that the $D_{2}$ release spectra of $\mathrm{W}$ and $\mathrm{W}$-Ta are different in shape. The release spectrum of $\mathrm{W}$ features two components at $\sim 470-510 \mathrm{~K}$ and $\sim 750 \mathrm{~K}$, while the spectrum of WTa has components at $\sim 490 \mathrm{~K}$ and $\sim 670 \mathrm{~K}$.

The release spectrum of $\mathrm{W}$ exhibits strong fluence dependence. The number and position of the release peaks remain the same, but redistribution of their intensities occurs. At lower fluence of $\sim 5^{*} 10^{25} \mathrm{~m}^{-2}$, the low-temperature peak at $\sim 470 \mathrm{~K}$ dominates the total release while at higher fluences the high-temperature component at $\sim 750 \mathrm{~K}$ is dominant. 
In the high fluence range of $3.5^{*} 10^{26}-10^{27} \mathrm{~m}^{-2}$, the total retention is systematically higher in $\mathrm{W}$ than in W-Ta.

From the correlation between TDS spectra and blistering patterns, we conclude that trapping in the sub-surface cavities corresponding to blisters is the predominant trapping mechanism in $\mathrm{W}$ for large fluences of high-flux plasma. Consequently, the retention is lower in $\mathrm{W}$-Ta at large fluence because of weaker blistering.

\section{Acknowledgments}

This work, supported by the European Communities under the contract of Associations between EURATOM and SCK•CEN, was carried out within the framework of the European Fusion Development Agreement. The views and opinions expressed herein do not necessarily reflect those of the European Commission.

\section{References}

[1] G. Federici, C.H. Skinner, J.N. Brooks, J.P. Coad, C. Grisolia, A.A. Haasz, A. Hassanein, V. Philipps, C.S. Pitcher, J. Roth, W.R. Wampler and D.G. Whyte, Nucl. Fusion 41 (2001) 12R.

[2] P. Gumbsch, J. Nucl. Mater. 323 (2003) 304312.

[3] T. Hirai, G. Pintsuk, J. Linke, M. Batilliot, J. Nucl. Mater. 390-391 (2009) 751-754.

[4] J. Linke, T. Loewenhoff, V. Massaut, G. Pintsuk, G. Ritz, M. Rodig, A. Schmidt, C. Thomser, I. Uytdenhouwen, V. Vasechko and M. Wirtz, Nucl. Fusion 51 (2011) 073017.

[5] M. Rieth, D. Armstrong, B. Dafferner, S. Heger, A. Hoffmann, M.-D. Hoffmann, U. Jantsch, C. Kübel, E. Materna-Morris, J. Reiser, M. Rohde, T. Scherer, V. Widak, H. Zimmermann, Advances in Science and Technology Vol. 73 (2010) pp 11-21.

[6] M. Wirtz, J. Linke, G. Pintsuk, L. Singheiser and I. Uytdenhouwen, Phys. Scr. T145 (2011) 014058.Causey] R. Causey, J. Nucl. Mater. 300 (2002) 91-117.

[7] R. A. Causey, J. Nucl. Mater. 300 (2002) 91117.

[8] Y. Zayachuk, G. Bousselin, J. Schuurmans, Yu. Gasparyan, I. Uytdenhouwen and G. Van Oost, Fus. Eng. Des. 86 (2011) 1153-1156.

[9] Y. Zayachuk, M. H. J. 't Hoen, I. Uytdenhouwen and G. Van Oost, Phys. Scr. T145 (2011) 014041.

[10] Y. Zayachuk, M. H. J. 't Hoen, P. A. Zeijlmans van Emmichoven, I. Uytdenhouwen, and G. van Oost, Nucl. Fusion 52 (2012) 103021.

[11] K. Schmid, V. Rieger, A. Manhard, J. Nucl. Mater., 426 (2012) 247-253.

[12] W. Wang, J. Roth, S. Lindig and C. H. Wu, J.
Nucl. Mater. 299 (2001) 124-131.

[13] G.J. van Rooij, V.P. Veremiyenko, W.J. Goedheer, B. de Groot, A.W. Kleyn, P.H.M. Smeets, T.W. Versloot, D.G. Whyte, R. Engeln, D.C. Schram and N.J. Lopes Cardozo, Appl. Phys. Lett. 90 (2007) 121501.

[14] Y. Zayachuk, M. H. T. 't Hoen, P. A. Zeijlmans van Emmichoven, I. Uytdenhouwen and G. van Oost, PSI-2012, poster P3-69.

[15] M. H. J 't Hoen, B. Tyburska-Pueschel, K. Ertl, M. Mayer, J. Rapp, A. W. Kleyn and P. A. Zeijlmans van Emmichoven, Nucl. Fusion 52 (2012) 023008.

[16] O. V. Ogorodnikova, J. Roth, and M. Mayer, Journal of Applied Physics, 103 (2008) 034902.

[17] A. van Veen, H. A. Filius, J. de Vries, K. R. Bijkerk, G. J. Rozing and D. Segers, J. Nucl. Mater., 155-157 (1988) 1113.

[18] M. Balden, S. Lindig, A. Manhard, V.Kh, Alimov, O. Ogorodnikova, J. Roth, PFMCFEMaS-2011, poster P51A.

[19] O.V. Ogorodnikova, J. Roth, M. Mayer, J. Nucl. Mater. 373 (2008) 254-258.

[20] Landolt-Börnstein, Group III, "Crystal and Solid State Physics", Volume, 11, SpringerVerlag.

[21] D. Nguyen-Manh, M. Muzyk, K. J. Kurzydlowski, N. L. Baluc, M. Rieth and S. L. Dudarev, Key Engineering Materials, 465 (2011) 15-20.

[22] K. Sakaki, T. Kawase, M. Hirato, M. Mizuno, H. Araki, Y. Shirai, M. Nagumo, Scripta Materialia, 55 (2006) 1031-1034. 

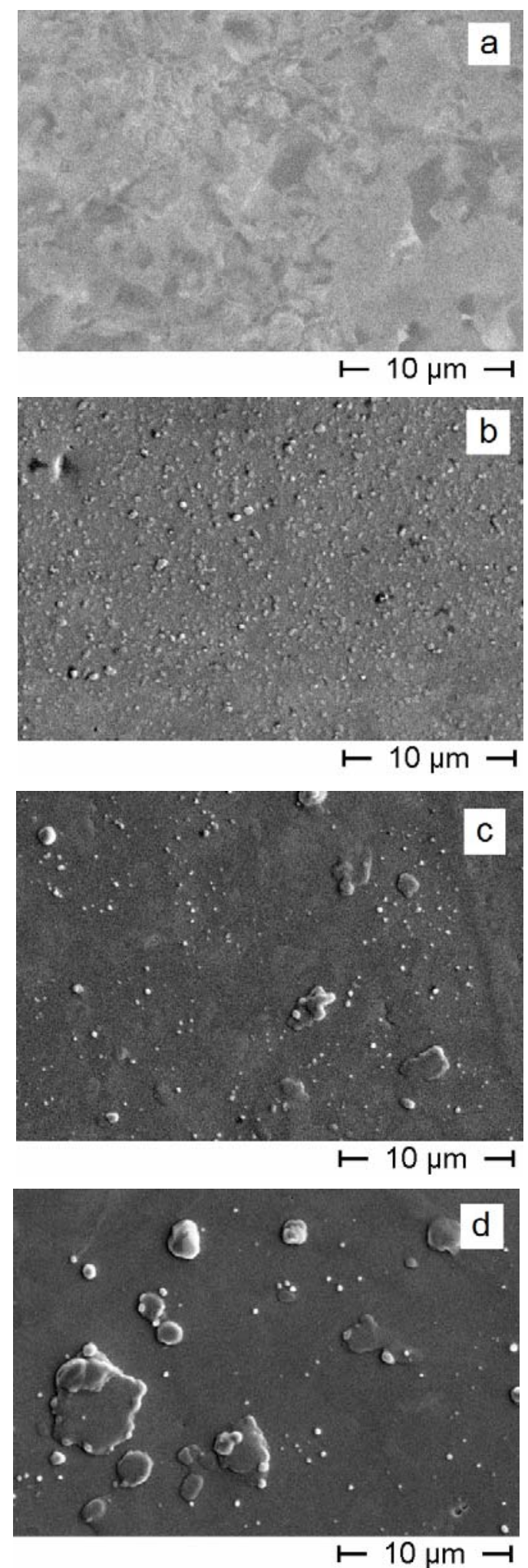

Fig. 1 The blistering patterns on the surfaces of $\mathrm{W}$ samples: (a) unexposed; exposed to (b) 1 reference shot (fluence $5^{*} 10^{25} \mathrm{~m}^{-}$ ${ }^{2}$ ), (c) 7 reference shots (fluence $3.5^{*} 10^{26} \mathrm{~m}^{-2}$ ); (d) 20 reference shots (fluence $10^{27} \mathrm{~m}^{-2}$ ). 

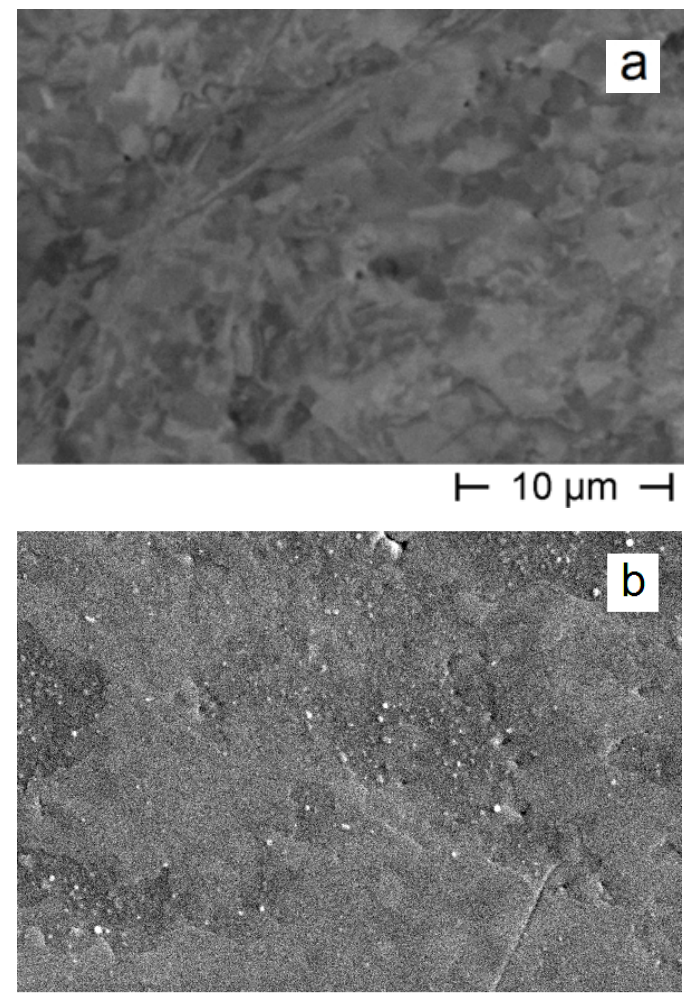

$\vdash 10 \mu \mathrm{m} \neg$

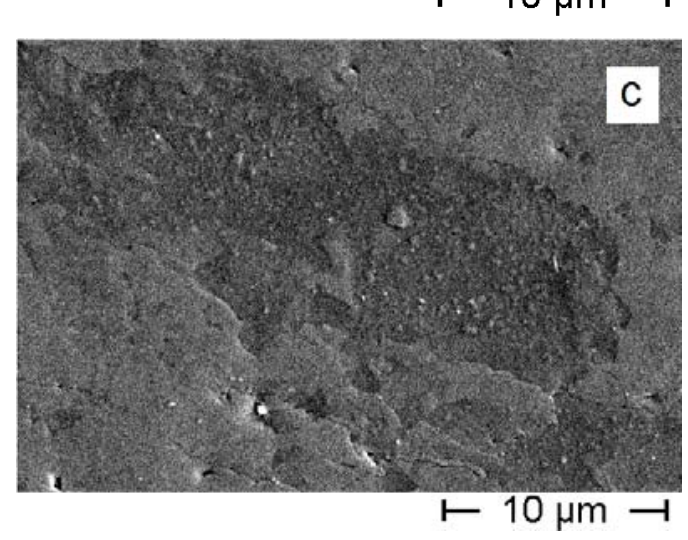

Fig. 2 The blistering patterns on the surface of W-5\%Ta samples (a) unexposed; exposed to (b) 7 reference shots (fluence $3.5^{*} 10^{26} \mathrm{~m}^{-2}$ ); (c) 20 reference shots (fluence $10^{27} \mathrm{~m}^{-2}$ ). 

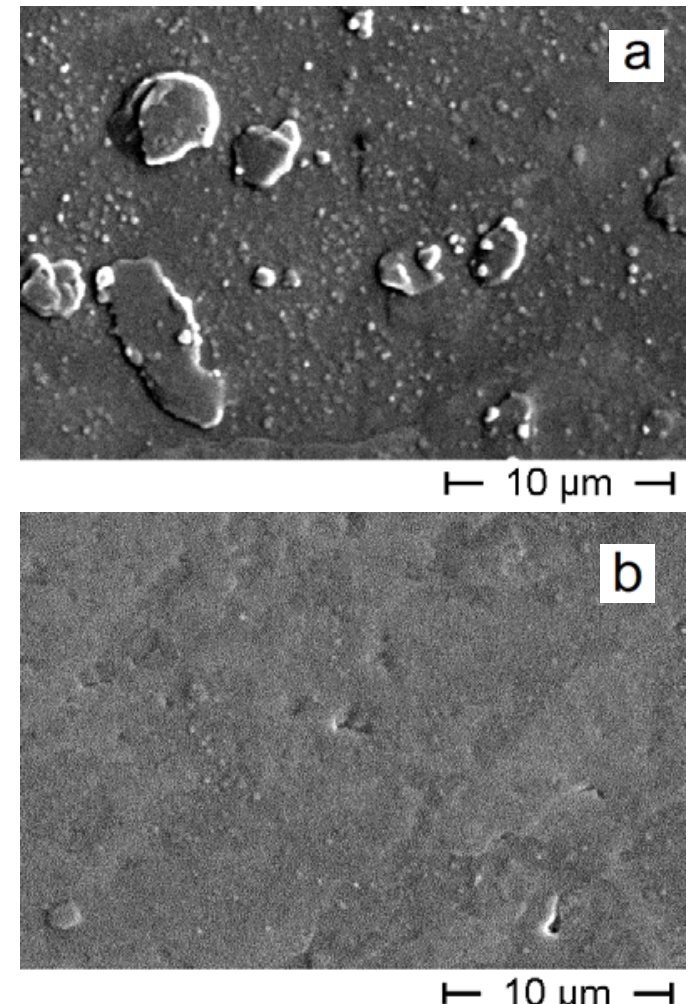

Fig. 3 The blistering pattern on the surface of a) W sample; b) W-5\%Ta sample, which were exposed to 20 reference shots (fluence $10^{27} \mathrm{~m}^{-2}$ ) and underwent TDS and additional exposure to a single reference shot. 


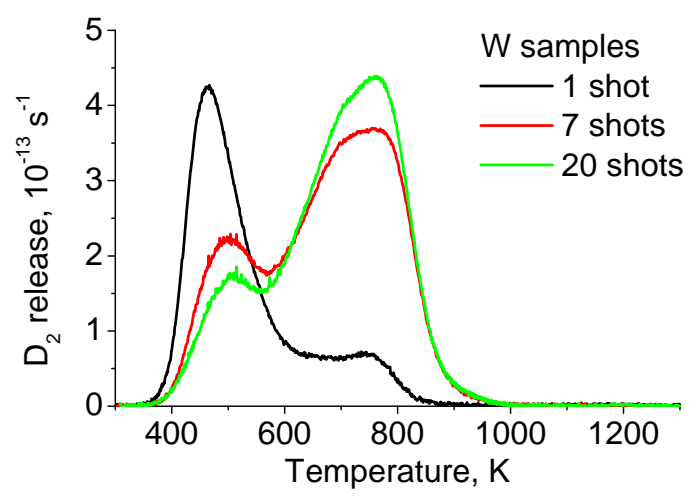

Fig. 4 TDS spectra of W samples exposed to different accumulated fluences. 


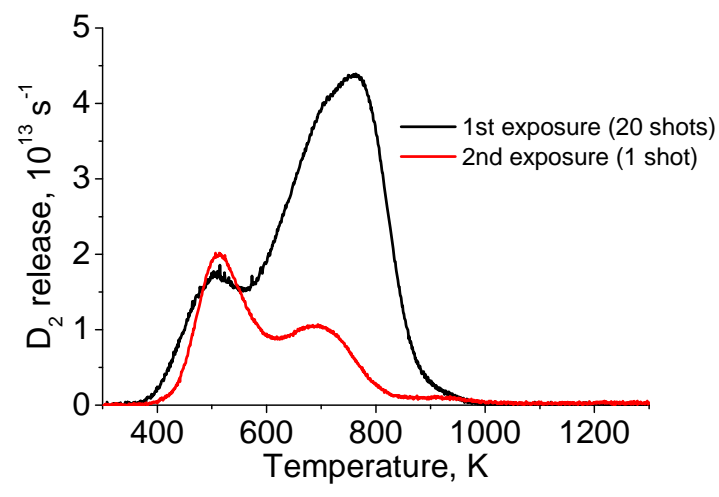

Fig. 5 TDS spectra of W sample after first exposure to 20 reference shot and subsequent exposure to one reference shot. 


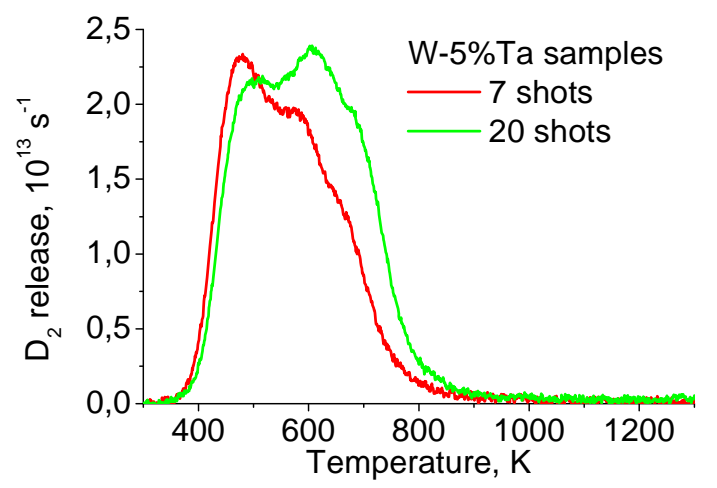

Fig. 6 TDS spectra of W-5\%Ta samples exposed to different accumulated fluences. 


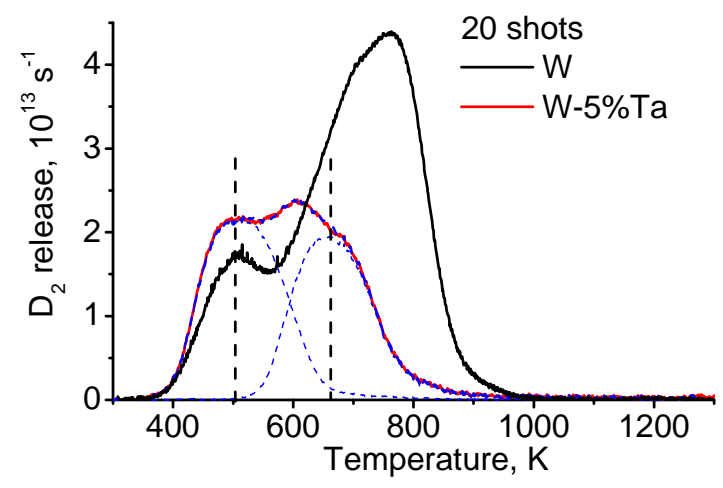

Fig. 7 Comparison of $\mathrm{D}_{2}$ release spectra of $\mathrm{W}$ and $\mathrm{W}-5 \%$ Ta exposed to high accumulated fluence $\left(10^{27} \mathrm{~m}^{-2}\right)$. The release spectrum of $\mathrm{W}-5 \% \mathrm{Ta}$ is decomposed into low- and high-temperature components. 


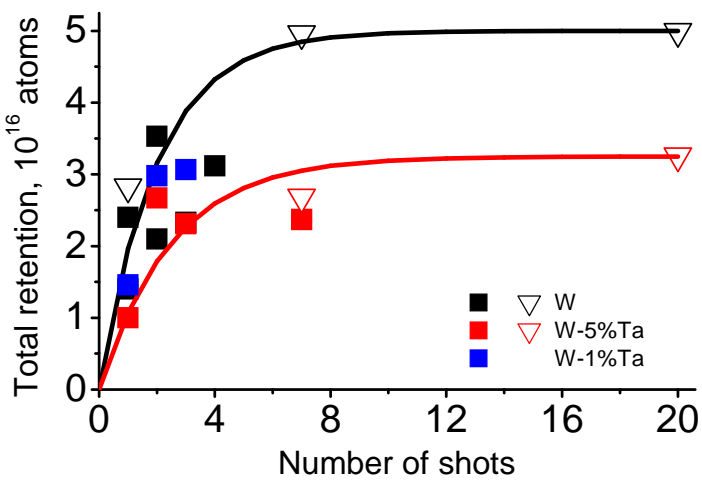

Fig. 8 Dependence of the total deuterium retention on the number of plasma shots, for W, W-1\%Ta and W-5\%Ta. Hollow symbols correspond to accumulating exposures, filled symbols - to the exposures where TDS measurements were performed after each shot. The lines are to guide the eye. 